\title{
Okun coefficients and participation coefficients by age and gender
}

\author{
Andrew Evans $\mathbb{B}$
}

Correspondence:

andrew.evans@mq.edu.au Macquarie University, Sydney, NSW 2109, Australia

\begin{abstract}
Estimates of the Okun coefficient are made for Australian workers grouped by age and gender using an unobserved components model. By analogy we define and estimate a participation coefficient which measures the cyclical response of the labour force participation rate to cyclical output shocks. The trend and cycle decomposition methodology used here leads to higher absolute estimates of the Okun coefficient than those typically found in the literature, although we find a pattern of variation in the coefficient by age and gender which is typical. We also find that, in aggregate, participating males in the middle age groups tend to stay in the labour force throughout the business cycle whereas females of the same age tend to participate procyclically. This has policy implications for attempts to increase the rate of participation of particular groups by age and gender following a cyclical downturn.
\end{abstract}

JEL Classification: C32, E32, J21

Keywords: Okun's Law, Labour force participation, Trend and cycle decomposition

\section{Introduction}

One of the most robust historical relationships in macroeconomics has been the negative relationship between unemployment and output growth as described by Okun (1962). This knowledge alone is not useful for guiding policy prescriptions without differentiating between the permanent and transitory components of unemployment and output. Structural or institutional change is necessary to influence the permanent trend whereas short-run policy initiatives are likely to affect only the transitory cycle. The response of cyclical unemployment to cyclical output shocks is of particular interest to policymakers. In this research, a trend and cycle decomposition is performed on the unemployment rate and the log of real GDP, and the cyclical components are interpreted as measures of the unemployment gap and output gap respectively. The estimated gaps are used to generate estimates of the Okun coefficient for workers grouped by age and gender.

The behaviour of the labour force participation rate $^{1}$ during the business cycle also needs to be considered because, without it, the unemployment rate is an incomplete indicator of the level of unutilised labour. Discouraged workers who transition from unemployment to non-participation during a recession may mask the true number of people who want more work. Participation was identified as a key driver of economic

(c) The Author(s). 2018 Open Access This article is distributed under the terms of the Creative Commons Attribution 4.0 International License (http://creativecommons.org/licenses/by/4.0/), which permits unrestricted use, distribution, and reproduction in any medium, provided you give appropriate credit to the original author(s) and the source, provide a link to the Creative Commons license, and indicate if changes were made. 
growth, improvement in living standards and community prosperity in the Intergenerational Report (Commonwealth of Australia 2015). Usually, the long-run trends affecting participation are of most interest to policymakers, such as the changing age structure of the population, migration effects and the participation of females and the elderly in the workforce, but cyclical effects also need to be understood. Policy initiatives which are intended to increase participation in a given context need to be designed either to influence the trend or the cyclical component. In this research, the focus is the business cycle behaviour of participation. We define a participation coefficient by analogy to the Okun coefficient which measures the cyclical response of the participation rate to output.

In the literature, the decomposition of macroeconomic time series is often performed using a Hodrick-Prescott filter (hereafter HP). Shortcomings of the approach are well known, arising from the requirement to choose a value for the smoothness parameter which controls the relative variance of trend and cycle components. The apparent behaviour of the HP cycle may be to some degree an artefact of the filtering process rather than a reflection of characteristics of the true data-generating process (Harvey and Jaeger 1993). For a recent criticism of the HP filter, see Hamilton (2017). As an alternative, we use the structural time series model developed by Harvey (1985) to make maximum likelihood estimates of unobserved trend and cycle components. The key advantage of the unobserved components (UC) model is that the components are estimated using a statistical model rather than being imposed by the structure and parameters of the HP filter. A multivariate model of output, unemployment, participation and total hours worked which incorporates a common business cycle is jointly estimated to extract the trends and cycles. Estimates are made separately by age and gender for Australian data. The first contribution of this paper is a new set of estimated Okun coefficients derived from the relative magnitude of the unemployment and output cycles. The second contribution is a set of participation coefficients which reveal the estimated magnitude of the cyclical response of labour force participation by age and gender to shocks to cyclical output.

In Section 2 literature is reviewed which provides theoretical grounds for and empirical description of the business cycle behaviour of unemployment and participation. Section 3 describes the labour market data used for the empirical analysis and illustrates some of the salient features of particular age and gender groups. A detailed specification of the empirical model is provided in Section 4. Empirical results are given in Section 5 and the estimated trend and cycle components are illustrated graphically. Estimates of the Okun and participation coefficients are given by age and gender and a comparison is made with estimates of the former made in the literature. Section 6 concludes the paper.

\section{Theoretical background}

\subsection{Okun's Law}

A negative relationship between output and unemployment can be easily motivated by theory, for example, the assumption of a Cobb-Douglas production function with a labour force of fixed size yields an approximately negative linear relationship between log output and the unemployment rate, with sensitivity determined by the output elasticity of labour input. Most studies focus simply on the empirical relationship, such as the relationship between first differences described by Okun (1962): 


$$
\Delta u_{t}=\alpha-\beta \Delta y_{t}+\varepsilon_{t},
$$

where $\Delta u_{t}$ is the change in the unemployment rate, $\Delta y_{t}$ is percentage change (or log change) in a measure of real output such as GDP and $\varepsilon_{t}$ is an error term. $\beta$ is interpreted as the Okun coefficient ${ }^{2}$. A shortcoming of this representation is that it implies that the relationship between $\Delta u_{t}$ and $\Delta y_{t}$ is purely contemporaneous. The model can be improved easily by adding lagged terms in both variables:

$$
\Delta u_{t}=\alpha+\sum_{i=1}^{p} \gamma_{i} \Delta u_{t-i}+\sum_{j=0}^{q} \beta_{j} \Delta y_{t-j}+\varepsilon_{t} .
$$

The Okun coefficient can also be interpreted as the long-run impact of $\Delta y_{t}$ on $\Delta u_{t}$ (also 'long-run multiplier' or 'dynamic beta') which can be derived from the coefficient estimates as (Harvey 1993, 159)

$$
\beta=\frac{\sum_{j=0}^{q} \beta_{j}}{\left(1-\sum_{i=1}^{p} \gamma_{i}\right)} .
$$

A difficulty which remains using this approach is that there is no explicit distinction made between temporary and permanent shocks acting through $\Delta y_{t}$. Another expression for the relationship between unemployment and output (similar to the 'gap version' described by Okun (1962)) is

$$
\left(u_{t}-u_{t}^{*}\right)=-\beta\left(y_{t}-y_{t}^{*}\right)+\varepsilon_{t} .
$$

Different interpretations of $y_{t}^{*}$ may apply depending on the context of the research. In Okun's original paper, it represented potential output, the amount the economy could produce under conditions of full employment, and the econometric model was used to generate estimates of potential output. In this paper, we interpret $y_{t}^{*}$ as the (log) natural level of output when the economy is operating at sustainable full capacity. This level will vary though time depending on many factors we have not explicitly modelled, such as the level of demand and institutional constraints. It follows that $u_{t}^{*}$ can be interpreted as the equilibrium rate of unemployment which should prevail when output is being produced at its natural rate. It must be emphasised that there would be a conceptual difference between what is being measured by the parameter $\beta$ in each of Eqs. 1, 3 and 4, but each of them are sometimes described as 'the Okun coefficient' in the relevant context.

A trend and cycle decomposition of both $y_{t}$ and $u_{t}$ will be made in which the estimated trend will be interpreted as the time-varying equilibrium $\left(y_{t}^{*}\right.$ or $\left.u_{t}^{*}\right)$ and the cycle as a measure of the gap represented in Eq. 4. By construction, the gaps will be stationary with zero mean. The sensitivity of the unemployment gap to the output gap will be interpreted as a measure of the Okun coefficient. Separate estimates of the coefficient will be made by gender and by age bracket.

There is ample evidence that estimates of the Okun coefficient vary across countries which is likely to reflect different institutions, policy settings and cultural differences between them. There are mixed results regarding the stability of estimates through time within country but, on balance, there is evidence that the relationship between output and unemployment may vary due to structural changes which occur over time. Ball et al. (2013) considered whether Okun's Law was still robust some 50 years after Okun's original paper and found it to be strong and stable 
in most countries, but with significant variation between countries. They rejected the idea that the relationship has broken down after the most recent recessions leading to claims of so-called jobless recoveries in the USA. Lee (2000) finds statistically significant Okun coefficients across a range of OECD countries but with great variation in magnitude. Some of the variation is attributed to higher rigidity in some of the European labour markets and Japan compared to the USA (see also Nickell (1997)). Lee also finds strong evidence of structural breaks mostly in the early 1970s but which also vary by country. Dixon et al. (2017) estimated an Okun coefficient using a panel of 20 OECD countries (including Australia) for the period 1985-2013, having controlled for the influence of labour market institutions such as union coverage, unemployment insurance and employment protection legislation. They rejected the hypothesis that the Okun coefficient had remained the same over time in their base model but were able to explain most of the increase using the share of temporary workers in the workforce, amongst other changes to institutional variables. Further cross-country studies of the Okun coefficient can be found in International Monetary Fund (2010) and Moosa (1997)).

There have also been many studies which consider a potential non-linear relationship between output and unemployment. Cuaresma (2003) specifies a model with a regimedependent Okun coefficient which allows an asymmetric response of unemployment to output depending on whether the economy is in either of two regimes which correspond approximately with expansion or recession. The absolute sensitivity measured by the Okun coefficient is found to be approximately twice as large when the economy is in recession. Holmes and Silverstone (2006) estimate a model with two forms of asymmetry whereby, in the first case, the Okun coefficient depends on two regimes defined by positive and negative cyclical output and, in the second case, the absolute value of the coefficient depends on the sign of the shock. The authors find evidence of both forms of asymmetry. Lee (2000) finds mixed evidence of asymmetry depending on the specific country. Dixon et al. (2017) are unable to reject the hypothesis of symmetry. Bodman $(1998,410)$ finds evidence of non-linear behaviour in unemployment in Australia, in particular he finds that shocks are more persistent in recessions than expansions, which is broadly suggestive of hysteresis in the labour market.

There are sound reasons to expect different responses to the business cycle amongst different age and gender groups. For example, younger workers are likely to have less experience than older workers and have less employment protection (such as may occur under a temporary contract) and so be more likely to suffer involuntary job loss in a recession. Equally, recent school-leavers are likely to take into account the state of the business cycle when they choose between higher education and joining the labour force (Dellas and Sakellaris 2003). Both of these factors would contribute to greater cyclicality of youth unemployment. Unemployment for males may be more cyclical than for females because they have higher representation in cyclical activities like building construction (Zanin 2014). Some females with young children may elect to leave the labour force during an economic downturn, thereby not affecting the official unemployment measure. Lastly, older workers may have a difficult choice to make in a downturn between unemployment and participation given the difficulty they may face re-joining the workforce at a later date, so there may be a more complex interaction between cyclical unemployment and participation for older workers. 
In this research the focus will be on the differences in coefficients for age and gender groups rather than on possible asymmetry and stability of the coefficients through time. The model will have an inherently linear relationship between output and unemployment shocks. However, the basic framework for estimating the Okun coefficient will be extended to allow joint estimation of the sensitivity of unemployment and labour force participation to the business cycle, to capture any interaction between them during the cycle.

\subsection{Cyclical participation}

Mincer (1966) put forward theories to explain cyclical movement of workers in and out of the labour force. The added-worker effect was used to explain the type of worker who is more likely to join the labour force in an economic downturn to compensate for the potential loss of income by another household member who may become unemployed. Historically, this concept was applied mainly to married women who sought to add to household income to mitigate loss of income by their spouse. The addedworker effect would generate counter-cyclical participation. Mincer also described the discouraged-worker effect which posited that some unemployed workers stop looking for work in an economic downturn (and therefore become non-participants) because they perceive that the probability of finding work is so low it is not worth searching. This same group are likely to re-join the labour force when the economy improves, generating procyclical participation. The added-worker and discouraged-worker effects can coexist and aggregate labour market data tends to reveal only the net contribution of the two effects.

It has been argued by Dixon et al. (2004) that in relation to the Australian economy it is not credible to try and explain the variation in the participation rate with a sole focus on the movement of discouraged workers between the states of unemployment and non-participation. In the first place, gross flow data ${ }^{3}$ reveals that the largest average flows are between non-participation and employment. The magnitude of these flows is almost twice as large as those between non-participation and unemployment (Dixon et al. 2015, 2530) which suggests that they are an important part of the overall dynamics of the labour market. Similar observations have been made in other markets including the USA (Blanchard and Diamond 1990, 91-92). Dixon et al. (2004) find that the main influence on the growth rate of the labour force is the size of the net flow between non-participation and employment. Dixon et al. (2015) argue that it is essential to treat flows to and from non-participation as endogenous within a system also including employment and unemployment flows. Other studies which treat participation as endogenous to examine its behaviour during the business cycle can be found in Darby et al. (2001), Elsby et al. (2015) and an Australian study by Ponomareva and Sheen (2013).

The Intergenerational Report (Commonwealth of Australia 2015) projects that participation in Australia will decline over the next 40 years due to a changing age demographic which will see a relative decline in age cohorts of people where participation tends to be highest. This is despite an anticipated increase in participation within each cohort. On the other hand, the health of older Australians is improving so that a greater number of them are capable of continuing to work beyond traditional retirement age if circumstances permit. The importance of increasing participation 
to the Government is reflected in policy measures to support the participation not only of mature-age job seekers but also youth, women and parents (Commonwealth of Australia 2015, 96). Even though the report focusses on long-term trends, we observe that temporary output shocks can have a long-term effect on participation and unemployment if there is hysteresis. Duval et al. (2010) find that severe recessions have a significant and persistent impact on the level of participation in a panel of 30 OECD countries including Australia. They find that aggregate participation may be $1.5-2.5 \%$ lower 5 to 8 years after the previous cyclical peak before the commencement of the recession. Persistent or permanent impact on older workers may be explained by irreversible retirement decisions made in response to a recession, which can be influenced by early retirement incentives arising from policy initiatives or those embedded in pension schemes (Duval et al. 2010). Persistent impact on the participation of younger workers may be explained by choices to enrol in longer programmes of higher education and training during a downturn. These findings show that it is important for policymakers to consider cyclical shocks to participation as well supporting long-term trend growth.

There has been much less empirical analysis of the cyclicality of participation than unemployment in the literature in most countries, including Australia. In macroeconomic studies of the USA, the size of the labour force has often been assumed to be acyclical as discussed in Erceg and Levin (2014), with participation sometimes modelled as a fixed percentage of the civilian population. Benati (2001) found evidence of procyclical participation at a business cycle frequency (a net discouraged-worker effect) in the USA at an aggregate level and for a number of age-sex groups. In many developed countries, participation rates declined following the Great Recession and attempts have been made to determine how much of the decline was cyclical and how much reflected a permanent change in labour supply, without universal agreement as to the conclusion. Erceg and Levin (2014) found evidence that cyclical factors accounted for most of the decline since 2007. Van Zandweghe (2012) found that participation was very weakly procyclical from 1948 to 2011 but that since 2007 the participation rate had become more sensitive to the state of the economy and that about half of the decline in participation from 2007 to 2011 could be attributed to cyclical factors.

The empirical relationship between participation and output cycles can be measured using an equation conceptually similar to Eq. 4 with the unemployment gap replaced by the participation gap. The estimated trend from a decomposition of the participation rate will incorporate all of the permanent influences on the level of participation such as changing demographics and attitudes towards gender and age in the workforce. The cycle component will be interpreted as the participation gap, a transient deviation of the current level from the permanent trend. The sensitivity of the participation gap to the output gap will be estimated by gender and age bracket.

\section{Australian labour market data}

We use seasonally adjusted monthly time series of the unemployment rate $\left(u_{t}\right)$ and labour force participation rate $\left(p_{t}\right)$ for 13 groups of workers: all persons, males, females and each gender separated into five 10-year age brackets. The youngest age bracket is 15-24 
years old, followed by 25-34 years old and so on up to 55-64 years old. The characteristic behaviour of unemployment and participation for each age bracket is illustrated in Fig. 1 from February 1978 to June 2017. For output we use the log of seasonally adjusted real quarterly GDP $\left(g_{t}\right)$ multiplied by 100 . We also make use of a seasonally adjusted series of total monthly hours worked in all jobs by all persons, from July 1978. Growth in hours worked over several decades mostly reflects population growth so we use the $\log$ of hours worked multiplied by 100 which we denote by $h_{t}$. Seasonally adjusted series are used in each case so that any seasonal pattern in the raw series which may appear to

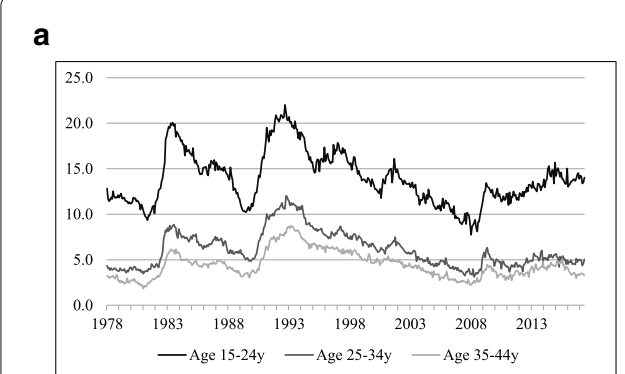

\section{b}

c

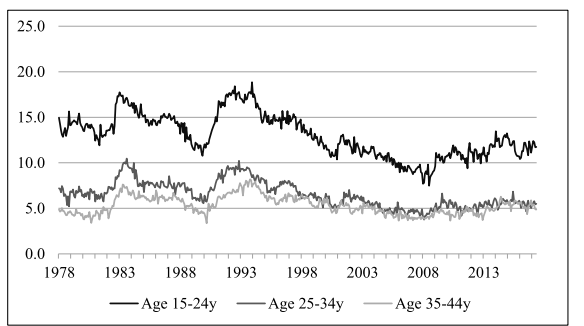

d
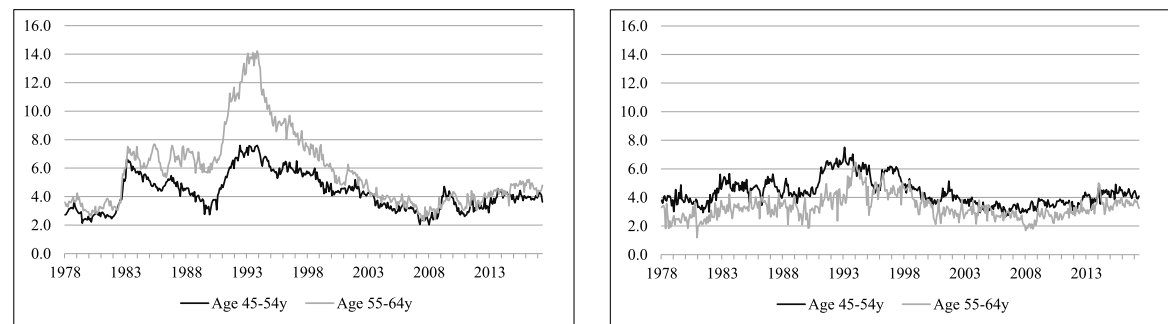

e

f

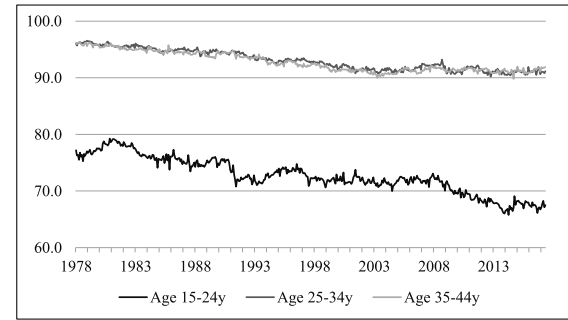

g

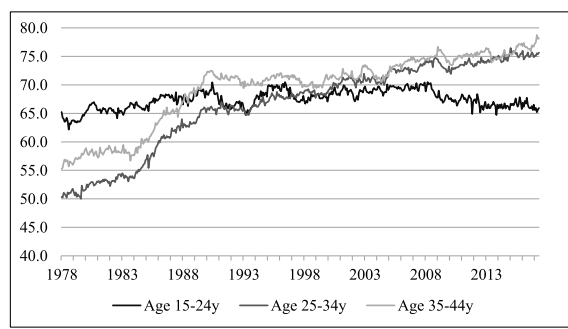

h
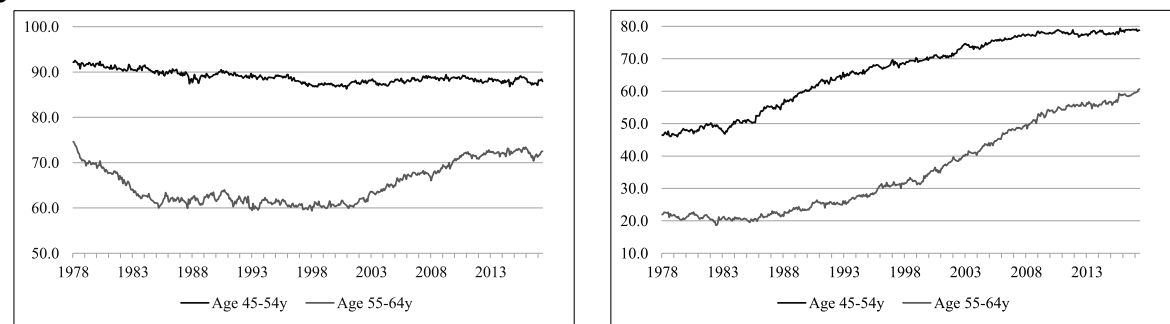

Fig. 1 Historic unemployment and participation rates by age bracket. a Male unemployment rate (age 15-44 years). b Female unemployment rate (age 15-44 years). c Male unemployment rate (age 45-64 years). d Female unemployment rate (age 45-64 years). e Male participation rate (age 15-44 years). f Female participation rate (age 15-44 years). $\mathbf{g}$ Male participation rate (age 45-64 years). $\mathbf{h}$ Female participation rate (age 45-64 years) 
be some form of annual cycle does not interfere with the estimation of the cycle component at a business cycle frequency. The relationships between output, unemployment and participation are the main interest in this research, whereas the monthly hours worked series is used primarily to assist in identifying a common cyclical component across the series. The estimation period used for our empirical results will be September 1980 to June 2017.

\section{Empirical model}

A trend and cycle decomposition methodology is required to generate estimates of gaps for output and the labour market series so that it is possible to measure the responsiveness of cyclical unemployment and participation to cyclical output shocks in a relationship analogous to the empirical relationships described by Eq. 4. Studies of Okun's Law in the literature have frequently made use of the HP filter to extract an estimate of the output gap and sometimes also the unemployment gap. A problem with the HP filter for this application is that the chosen smoothness parameter can have a dramatic effect on the relative variance of the trend and cycle components. In this research, an alternative decomposition methodology is used to generate maximum likelihood estimates of the components without prior restrictions on the relative magnitude of the trend and cycle variances.

\subsection{Multivariate unobserved components model with common cycle}

The following is a typical specification of an unobserved components model with stochastic trend and cycle components, mostly following the notation of Harvey (1985). The model has been represented in so-called state space form so that it can be estimated using the Kalman filter. The state space form requires a measurement equation in which an observable series is linearly related to a set of unobservable state variables. We will make a joint estimation of a system including output, unemployment, participation and hours worked, but first we present only the parts of the system relating to output in Eq. 5.

$$
\begin{array}{rlrl}
g_{t} & =\tau_{g t}+c_{t}+\varepsilon_{g t}, & & \varepsilon_{g t} \sim \text { iid }\left(0, \sigma_{\varepsilon g}^{2}\right), \\
\tau_{g t} & =\tau_{g t-1}+\beta_{g t-1}+\eta_{g t}, & \eta_{g t} \sim i i d\left(0, \sigma_{\eta g}^{2}\right), \\
\beta_{g t} & =\beta_{g t-1}+\zeta_{g t}, & \zeta_{g t} \sim \text { iid }\left(0, \sigma_{\zeta g}^{2}\right), \\
{\left[\begin{array}{c}
c_{t} \\
c_{t}^{*}
\end{array}\right]} & =\rho\left[\begin{array}{lr}
\cos (\lambda) & \sin (\lambda) \\
-\sin (\lambda) & \cos (\lambda)
\end{array}\right]\left[\begin{array}{c}
c_{t-1} \\
c_{t-1}^{*}
\end{array}\right]+\left[\begin{array}{c}
\kappa_{t} \\
\kappa_{t}^{*}
\end{array}\right], & & \kappa_{t}, \kappa_{t}^{*} \sim i i d\left(0, \sigma_{\kappa}^{2}\right) .
\end{array}
$$

The trend in $\log$ output is represented by $\tau_{g t}$, with slope $\beta_{g t}$, and the cycle by $c_{t}$. The irregular component $\varepsilon_{g t}$ can be interpreted as random noise or as a measurement error. The specification of the trend is very flexible in terms of the types of data-generating processes that it can be used to fit. In the most general form, both of the variances $\sigma_{\eta g}^{2}$ and $\sigma_{\zeta g}^{2}$ are freely estimated and, if both variances are non zero, the trend would be an integrated process of second order (in the literature this is usually referred to as a local linear trend (LLT) model). If the slope variance $\sigma_{\zeta g}^{2}$ is restricted to zero, then the trend will be a random walk with drift (also known as the local level (LOCL) model). If the level variance $\sigma_{\eta g}^{2}=0$ whilst $\sigma_{\zeta g}^{2}>0$ then the trend will be 'smooth' (known as the integrated random walk (IRW) model). 


\subsection{Cycle component}

The stationary cycle component $c_{t}$ in Eq. 5 is generated by a trigonometric stochastic cycle. The component $c_{t}^{*}$ is used in the construction of $c_{t}$ but is not otherwise used in the system. A complete description of the mechanics of the stochastic cycle for interested readers may be found in Harvey (1985) or Pelagatti (2016). One important observation is that the generated cycle will not be a smooth sinusoidal wave since the innovations $\kappa_{t}$ and $\kappa_{t}^{*}$ generate random variation in apparent amplitude and frequency. The central frequency is $\lambda \in[0, \pi]$ (with cycle period $=2 \pi / \lambda$ ), and $\rho \in[0,1]$ is known as the damping factor since it determines the portion of the previous cyclical value that is propagated into the next period. If $\rho<1$ then the cycle will be stationary. It can be shown that the cycle has a $\operatorname{ARMA}(2,1)$ reduced form, but with some complex cross-parameter restrictions (Harvey 1985, 219-220). An alternative autoregressive model of the cyclical component could have been used in Eq. 5 but the reason the stochastic cycle is preferred in economic business cycle analysis is that we can obtain a direct estimate of the period of cycle and of the damping factor which indicates the degree of persistence of cyclical shocks.

Next we add equations for the decomposition of the unemployment rate as shown in Eq. 6 .

$$
\begin{array}{rlrl}
u_{t} & =\tau_{u t}+\omega_{u} c_{t}+\varepsilon_{u t}, & & \varepsilon_{u t} \sim \text { iid }\left(0, \sigma_{\varepsilon u}^{2}\right), \\
\tau_{u t}=\tau_{u t-1}+\beta_{u t-1}+\eta_{u t}, & & \eta_{u t} \sim i i d\left(0, \sigma_{\eta u}^{2}\right), \\
\beta_{u t}= & \beta_{u t-1}+\zeta_{u t}, & & \zeta_{u t} \sim \operatorname{iid}\left(0, \sigma_{\zeta u}^{2}\right) .
\end{array}
$$

The trend specification is identical to that shown in Eq. 5 except that the unobserved components and their variances relate particularly to $u_{t}$. The common cycle component is evidenced by $c_{t}$ which appears in both Eqs. 5 and 6 . The cycle is multiplied by the scaling parameter $\omega_{u}$ in the equation for unemployment, whereas the equivalent parameter in the output equation is normalised to one. The motivation for using a common cycle is twofold. Firstly, it is an identification strategy, since there are fewer parameters to estimate than a model in which each economic variable has an independent cycle. Secondly, the idea sits neatly inside a macroeconomic framework in which there are one or more unobserved cyclical factors which drive the temporary fluctuations of a large number of indicators of activity, such as aggregate demand, output and production factor inputs. Any aggregate macroeconomic variable is likely to be measured with error or be affected by noise, so there is a perceived advantage in constructing a model which makes a joint estimation of a common unobserved factor from several related observable series. In this analysis, the common cycle can be interpreted as a proxy for the business cycle.

To elaborate on the role of the parameter $\omega_{u}$ in the common cycle model, we observe that the unemployment and output cycles are $\omega_{u} c_{t}$ and $c_{t}$ respectively. The cycles are perfectly correlated and the ratio of their variances is $\omega_{u}^{2}$. Equivalently, a one unit shock to $\kappa_{t}$ will generate a one unit shock to $c_{t}$ and $g_{t}$, and a shock of $\omega_{u}$ to $u_{t}$. So $\omega_{u}$ can be interpreted directly as the cyclical response of the unemployment rate to a cyclical shock in log output, which is one measure of the Okun coefficient. To emphasise the connection between the empirical model and theory as described in Section 2, the trend is being interpreted as the equilibrium level and the cycle is being interpreted as the gap, having also removed estimated measurement error. 
In a similar fashion, we add equations for the decomposition of the participation rate and hours worked to our system each using the same structure to model the trend and each referencing the same common cycle with scaling coefficients $\omega_{p}$ and $\omega_{h}$ respectively (the equations relating to participation and hours are not shown). We can interpret $\omega_{p}$ directly as the cyclical response of the participation rate to a cyclical shock in log output, which we refer to as the participation coefficient.

\subsection{Correlation between components}

In addition to the explicit relation between the variables arising from the common cycle component, it is possible that the irregular error components may be correlated. This feature would make the system analogous to a seemingly unrelated regression model in which shared driving factors not explicitly modelled manifest in correlated errors across equations. Restricted and unrestricted correlations between irregular components were investigated and the results suggested none were significantly different to zero except for the correlation between unemployment and participation irregular components $\varepsilon_{u}$ and $\varepsilon_{p}$. There are strong theoretical grounds to support possible correlation between this pair since measurement errors in one variable may be directly related to measurement errors in the other, for example a person misclassified as nonparticipating rather than unemployed in the labour market survey at time $t$ will generate an underestimate of both $p_{t}$ and $u_{t}$. In the models below, we allow unrestricted correlation between $\varepsilon_{u}$ and $\varepsilon_{p}$ (labelled $r \varepsilon_{u p}$ ) and we anticipate that the correlation will be positive. All the remaining pairs of irregular components were restricted to be uncorrelated.

Correlations between all the remaining innovations $\eta_{t}, \zeta_{t}$ and $\kappa_{t}$ were restricted to zero. This was important for model identification, but a detailed discussion of alternative models with correlated components is beyond the scope of this paper. For examples of correlated UC models, readers can refer to Morley et al. (2003), Sinclair (2009), Jaeger and Parkinson (1994) and Proietti (2004).

\subsection{Seasonality}

We use seasonally adjusted data for all four of the observable series but still found some residual seasonal patterns in the labour data and found it useful to augment the measurement equations with some lagged first differences of the observable series, principally around 12- and 24-month lags. To increase confidence that the common cycle component has been validly identified, it is important to take all possible steps to remove autocorrelation from the estimated residuals.

\subsection{Estimation method}

The Kalman filter is a recursive procedure which can be used to find estimates of the unobserved components of a model in state space form. Maximisation of a $\log$ likelihood function created from one step ahead prediction errors and their variances generates maximum likelihood estimates of the model parameters, which are used to generate optimal estimates of the time series of unobserved components. The filtered series provide optimal estimates of a component at time $t$ using only the information available at time $t$. A smoothing procedure can be applied 
to the filtered series using all of the information in the sample period to generate so-called smoothed estimates. Whilst smoothed estimates cannot be used for real-time prediction, they can be compared with the output from other filtering techniques which use the entire sample period such as the HP filter. For a description of filtering and smoothing algorithms, see Commandeur and Koopman (2007, 84-89).

\subsection{Mixed-frequency data}

The labour market series have monthly frequency whereas the GDP series is quarterly. We simply treat the non-calendar-quarter months as missing values in the log GDP series. These are easily handled within the state space framework and estimation by the Kalman filter. The prediction step will make a multi-step prediction over the missing values. The smoother will generate estimates for the missing values, but these would not be available in real time (Harvey 1985, 95). Given that GDP is a quarterly flow variable, there is no direct interpretation of the smoothed log GDP values generated for the missing months. In practical terms, the sum of monthly log differences will equal the quarterly log difference, by construction. As part of a joint estimation, we found that it was useful to include both monthly and quarterly data to identify the common business cycle.

\section{Results}

\subsection{Trend and cycle decomposition}

Three variations of the structure of the trend component were estimated, being LOCL, LLT and IRW as defined earlier. The IRW smooth trend model generated materially lower $\log$ likelihood than the other models so it was discarded. The LLT model with stochastic slope generated slightly higher log likelihoods than the LOCL model for both male and female data sets. However, the estimated variance of the slope parameters was not significantly higher than zero. Also, given high standard errors of coefficient estimates and poor convergence, the model was most likely underidentified, i.e. there was not sufficient information in the data to identify both slope and level variances. Accordingly, the LOCL model was chosen as the preferred model for the trend. All of the series contained an estimated common cycle component, and all but $g_{t}$ contained an irregular component. The estimated variance of the irregular innovations $\sigma_{\varepsilon g}^{2}$ was found not to be significantly higher than zero so it was subsequently restricted to zero.

Transformed variance parameters were estimated so that a positivity constraint could be applied when the parameters were transformed back into natural terms ${ }^{4}$. Similarly, a box constraint was applied to estimates of correlation coefficients and the cycle frequency parameter to ensure that the solutions lay within the relevant permissible range ${ }^{5}$. An arbitrary permissible range of 36-144 months was applied to the estimated cycle period. A summary of point estimates of key coefficients for males and females (all ages) are shown in Table 1. Full estimation results are shown in the Appendix Table 5. Graphs of the smoothed components are shown in Fig. 2.

Table 1 shows estimated cycle periods of approximately 82 months and 106 months for males and females respectively, which are a little longer than would typically be associated with the length of the business cycle but which are consistent with the prominent features 
Table 1 Model estimation

\begin{tabular}{|c|c|c|c|}
\hline & & Male & Female \\
\hline \multirow[t]{3}{*}{ Common } & Period (months) & 81.95 & 105.65 \\
\hline & $\rho$ & 0.9887 & 0.9898 \\
\hline & $\sigma_{\kappa}^{2}$ & 0.0253 & 0.0272 \\
\hline \multirow[t]{4}{*}{$\operatorname{GDP}\left(g_{t}\right)$} & $\sigma_{\varepsilon g}^{2}$ & & \\
\hline & $\sigma_{\tau g}^{2}$ & 0.1262 & 0.1398 \\
\hline & $\omega_{g}$ & 1.0000 & 1.0000 \\
\hline & $\mathrm{Q}(24) p$ val.** & 1.0000 & 0.9970 \\
\hline \multirow[t]{4}{*}{ Unemployment $\left(u_{t}\right)$} & $\sigma_{\varepsilon u}^{2}$ & 0.0067 & 0.0227 \\
\hline & $\sigma_{\tau u}^{2}$ & 0.0145 & 0.0143 \\
\hline & $\omega_{u}$ & -0.7699 & -0.5246 \\
\hline & $\mathrm{Q}(24) p$ val. & 0.1360 & 0.8570 \\
\hline \multirow[t]{4}{*}{ Participation $\left(p_{t}\right)$} & $\sigma_{\varepsilon p}^{2}$ & 0.0170 & 0.0184 \\
\hline & $\sigma_{\tau p}^{2}$ & 0.0096 & 0.0171 \\
\hline & $\omega_{p}$ & 0.1764 & 0.3437 \\
\hline & $\mathrm{Q}(24) p$ val. & 0.7360 & 0.1240 \\
\hline \multirow[t]{4}{*}{ Hours worked $\left(h_{t}\right)$} & $\sigma_{\varepsilon h}^{2}$ & 0.1510 & 0.1421 \\
\hline & $\sigma_{\tau h}^{2}$ & 0.0501 & 0.0089 \\
\hline & $\omega_{h}$ & 1.4277 & 1.9391 \\
\hline & $\mathrm{Q}(24) p$ val. & 0.1130 & 0.1580 \\
\hline Correl. Coeff. & $r \varepsilon_{\text {up }}$ & 0.7400 & 0.7846 \\
\hline
\end{tabular}

* $p$ value of the Q-statistic testing for no serial correlation in the one-step ahead prediction errors up to 24 lags

of the labour data for the sample period, i.e. cursory inspection of the unemployment rate series for all persons reveals local peaks in the rate after sharp economic downturns in 1983, 1992, 2001 and 2009, each 8 to 9 years apart. The estimated damping coefficients $(\rho)$ are approximately 0.99 which indicates that cyclical shocks are highly persistent.

The model generates joint estimates of the parameters, so estimates of common parameters such as the variance of the cycle innovation $\sigma_{\kappa}^{2}$ (in the third row of the table) will vary slightly depending on whether the cycle is estimated jointly with the male or female labour data. The magnitude of the output cycle relative to the common cycle $\omega_{g}$ is normalised to one. From the table, the responses of male cyclical unemployment to the output cycle is -0.77 whilst the corresponding female response is -0.52 . The negative signs of these coefficients indicate that unemployment is counter-cyclical. Hours worked is closely linked to total employment so it was anticipated that $h_{t}$ would be procyclical as indicated by the positive signs of $\omega_{h}$. The positive signs of $\omega_{p}$ were also anticipated, indicating that participation is procyclical for males and females. Non-zero estimates of the trend innovation variances $\left(\sigma_{\tau g}^{2}, \sigma_{\tau u}^{2}, \sigma_{\tau p}^{2}\right.$ and $\left.\sigma_{\tau h}^{2}\right)$ indicate that there are stochastic trends which are capturing the permanent shocks to the level of the variables, most notably for output. The positive sign of the estimated correlation coefficient $r \varepsilon_{u p}$ for males and females was anticipated due to the theoretical relationship between unemployment and participation described earlier. Full convergence was achieved at the solution for both males and females with no boundary solutions for any of the estimated parameters, which we interpret as indicating that the model is properly identified for these two data sets. The Q-statistics indicate that there is no significant serial correlation remaining in the one-step ahead prediction errors up to 24 lags for any of the signals. 


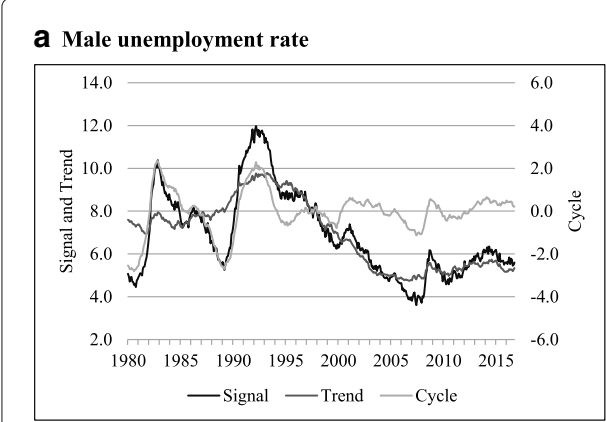

C Male participation rate

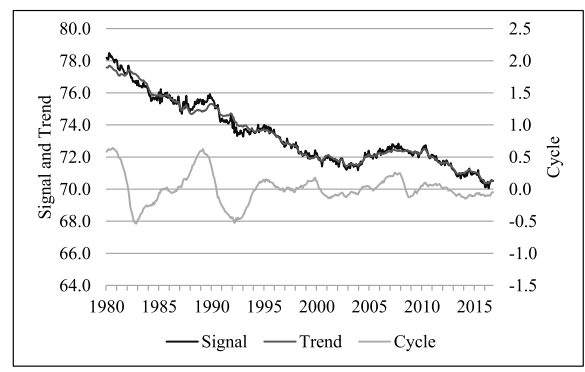

e $\log ($ GDP $) \times 100$

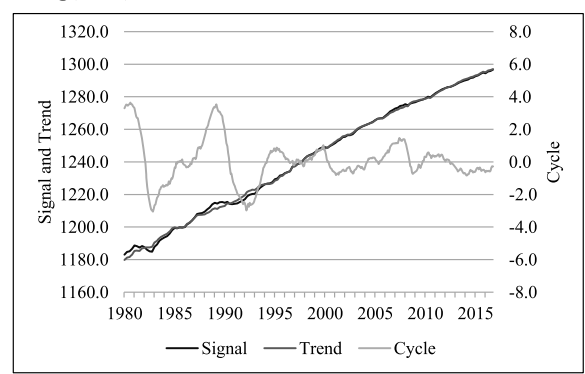

b Female unemployment rate

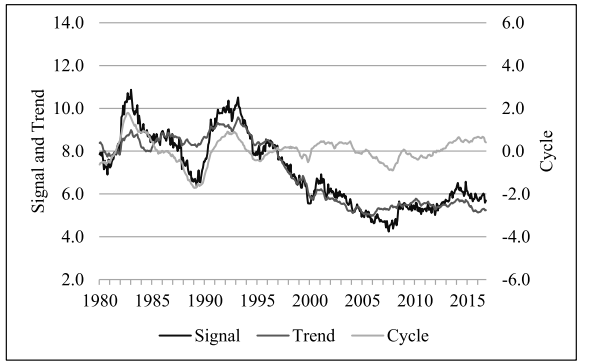

d Female participation rate

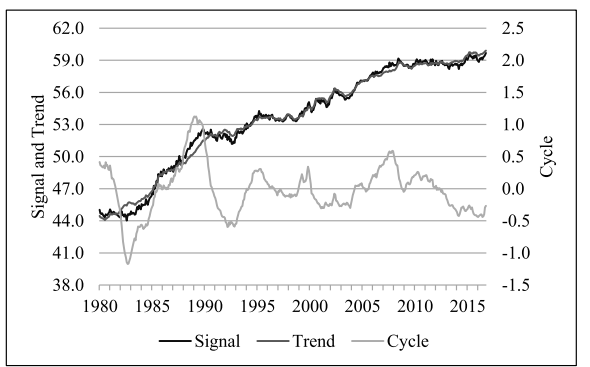

f $\log ($ monthly hours worked) $\times 100$

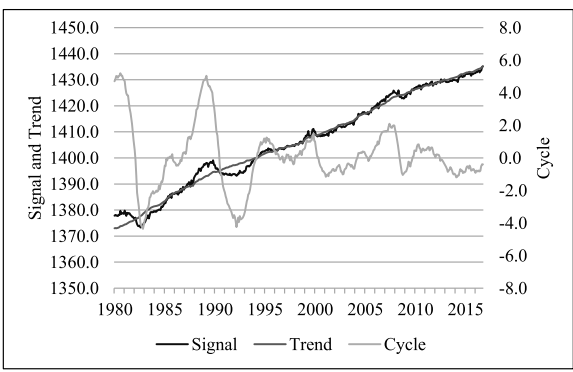

Fig. 2 Smoothed trend and cycle components. a Male unemployment rate. b Female unemployment rate. c Male participation rate. $\mathbf{d}$ Female participation rate. Notes: The smoothed components for $g_{t}$ and $h_{t}$ in graphs $\mathbf{l o g}(\mathrm{GDP}) \times 100$ and $\mathbf{f} \log ($ monthly hours worked) $\times 100$ were those jointly estimated with the male unemployment and participation series

\subsection{Comparing cycles across age brackets}

The same model was estimated for each of 13 data sets, being all persons, all males, all females and then males and females in each of the five age brackets. Figure 3 shows plots of smoothed cyclical components for selected age brackets on the same graph. To improve clarity, only the results for the youngest, middle and oldest age brackets are shown since the three series are sufficient to show how the character of some components changes with age. There is strong evidence for both males and females that unemployment is most cyclical for the youngest age bracket, judging by the relative amplitude of the cycle components. This is not surprising since a greater portion of younger people are likely to have casual or temporary work, the availability of which can vary quickly with the level of economic activity. Greater cyclicality of participation for this age group is also anticipated since 15-24-year-olds may often take into account the likely availability of jobs when they choose between joining the labour force and pursuing further education. Observation of the components for females 55-64 years old suggests that both unemployment and participation are less cyclical than for other groups. Whilst there have been stark increases 

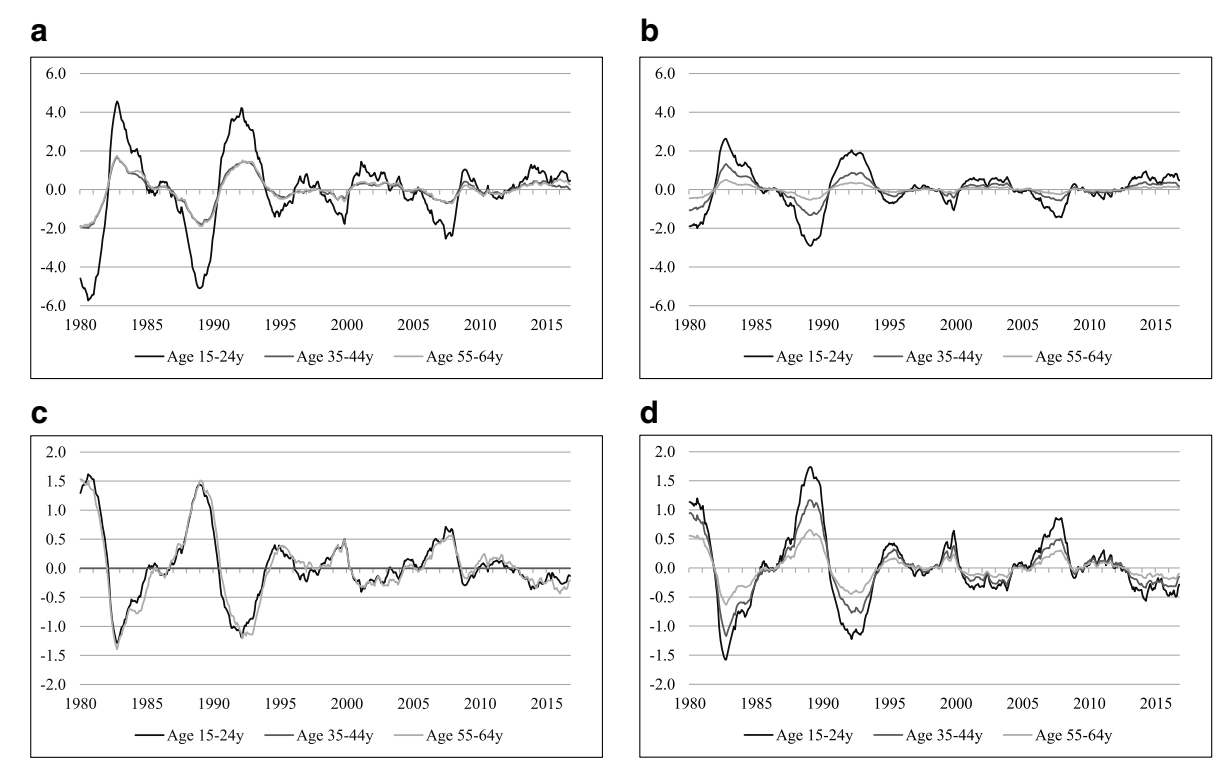

Fig. 3 Cycles by age bracket (youngest, middle, oldest). a Male unemployment cycle. b Female unemployment cycle. c Male participation rate cycle. $\mathbf{d}$ Female participation rate cycle

in employment and participation of older females over the last few decades, our results support the understanding that these have been predominantly trend changes rather than cyclical phenomena. On the other hand, for the older male age group, both unemployment and participation have prominent cycles which suggests that the level of economic activity is affecting their decision to participate in the labour force and that the type of employment opportunities for them are sensitive to the economic cycle.

The most striking observation in Fig. 3 is that there is essentially no participation cycle for males in the middle age bracket (the cycle virtually coincides with the horizontal axis) whereas there is a prominent cycles for females of the same age. This can be reconciled with the (arguably old-fashioned) idealised notion of a family unit with a middled-aged male primary wage earner who will typically stay in the labour force throughout the economic cycle, potentially moving only between employment and unemployment. By contrast a middle-aged female from the same family unit may have a higher tendency to move in and out of the labour force depending on the perceived likelihood of getting a job, to contribute secondary income to the family unit when opportunities are available.

\subsection{Interpretation of coefficient estimates}

The amplitude of the unemployment and participation cycles relative to the output cycle can be summarised concisely by interpreting $\omega_{u}$ as the Okun coefficient and $\omega_{p}$ as the participation coefficient as shown in Table 2. The first row of the table shows that the estimated signed Okun coefficient for all persons is -0.67 (in the literature this may typically be reported as 0.67 with an assumed but unstated negative relationship). The estimated participation coefficient for all persons is 0.22 (procyclical). The estimated Okun coefficient for all persons in Australia has the same sign but larger magnitude than recent estimates in the literature (for example, 0.54 by Ball et al. (2013)). The pattern in our estimates of higher coefficients for males vs. females of the same age and much higher 
Table 2 Estimated Okun and participation coefficients by age and gender

\begin{tabular}{|c|c|c|c|c|c|c|}
\hline Group & $\begin{array}{l}\text { Okun } \\
\text { coeffic. }\end{array}$ & s.e. & $95 \%$ Conf. & $\begin{array}{l}\text { Particip. } \\
\text { coeffic. }\end{array}$ & s.e. & $95 \%$ Conf. \\
\hline Persons (all age) & $-0.67^{* * *}$ & 0.097 & {$[-0.86,-0.48]$} & $0.22^{* * *}$ & 0.049 & {$[0.12,0.31]$} \\
\hline Male (all age) & $-0.77^{* * *}$ & 0.106 & {$[-0.98,-0.56]$} & $0.18^{* * *}$ & 0.044 & {$[0.09,0.26]$} \\
\hline Female (all age) & $-0.52^{* * *}$ & 0.082 & {$[-0.69,-0.36]$} & $0.34^{* * *}$ & 0.069 & {$[0.21,0.48]$} \\
\hline Male $15-24$ years & $-1.44^{* * *}$ & 0.177 & {$[-1.78,-1.09]$} & $0.41^{* * *}$ & 0.105 & {$[0.20,0.61]$} \\
\hline Male 25-34 years & $-0.81^{* * *}$ & 0.122 & {$[-1.05,-0.57]$} & 0.08 & 0.059 & {$[-0.03,0.20]$} \\
\hline Male 35-44 years & $-0.52^{* * *}$ & 0.081 & {$[-0.68,-0.36]$} & 0.00 & 0.048 & {$[-0.09,0.09]$} \\
\hline Male $45-54$ years & $-0.50^{* * *}$ & 0.073 & {$[-0.65,-0.36]$} & 0.12 & 0.072 & {$[-0.02,0.26]$} \\
\hline Male 55-64 years & $-0.57^{* * *}$ & 0.105 & {$[-0.78,-0.37]$} & $0.46^{* * *}$ & 0.142 & {$[0.18,0.73]$} \\
\hline Female $15-24$ years & $-0.87^{* * *}$ & 0.138 & {$[-1.14,-0.60]$} & $0.52^{* * *}$ & 0.126 & {$[0.27,0.77]$} \\
\hline Female $25-34$ years & $-0.56^{* * *}$ & 0.086 & {$[-0.73,-0.39]$} & $0.30^{* * *}$ & 0.102 & {$[0.10,0.50]$} \\
\hline Female $35-44$ years & $-0.39^{* * *}$ & 0.078 & {$[-0.54,-0.24]$} & $0.34^{* * *}$ & 0.097 & {$[0.16,0.53]$} \\
\hline Female $45-54$ years & $-0.31^{* * *}$ & 0.070 & {$[-0.45,-0.18]$} & $0.46^{* * *}$ & 0.125 & {$[0.22,0.71]$} \\
\hline Female $55-64$ years & $-0.16^{* *}$ & 0.071 & {$[-0.30,-0.02]$} & 0.20 & 0.131 & {$[-0.06,0.45]$} \\
\hline
\end{tabular}

Significance at $1 \%, 5 \%$ and $10 \%$ indicated by ${ }^{* * *},{ }^{* *},{ }^{*}$ respectively

coefficients for the youngest age group (15-24 years) are typical of the pattern found in the literature (for example, 1.14 for males $15-24$ years, 0.76 for females $15-24$ years by Dixon et al. (2017) for a panel of 20 OECD countries, and 1.10 for males 15-24 years, 0.61 for females 15-24 years by Zanin (2014) for Australia). The different patterns of cyclicality of participation for males and females are visible in the table. For the middle age brackets 25-54 years, the participation coefficients for males are small and not significant, whereas they are positive and significant at $1 \%$ for females, which supports our earlier graphical interpretation of the prominence of participation cyclicality for females in the middle age groups. The participation coefficients for the oldest and youngest age groups are also positive and significant except for the oldest female group ${ }^{6}$.

This research is useful for policymakers because it highlights the cyclicality of unemployment and participation for specific age and gender groups, and in particular, it provides higher estimates of the cyclicality than typically reported in the literature. In addition to their stated focus on the long-term trend, the cyclicality of participation may be of concern to the Government because of the risk that a person who leaves the labour force in a cyclical downturn may become a permanent non-participant. The importance of the persistence of participation is explicitly recognised in the Intergenerational Report which stresses the need to 'encourage those currently not in the workforce, especially older Australians and women, to enter, re-enter and stay in work' (Commonwealth of Australia 2015, iii). The analysis in this research uses aggregate historic data which naturally includes the impact of any existing policy initiatives, and is not designed to identify the effectiveness of any specific policy. However, if the Government is concerned about the potential decline in participation in a downturn, particularly amongst certain groups such as females in the middle age brackets, then the results indicate that there is cyclical behaviour which could be the target of further policy support. The types of support suggested in the Intergenerational Report (Commonwealth of Australia 2015, 96) include the provision of flexible and affordable child care and 
early learning facilities, including fee assistance rebates for parents and prospective parents $^{7}$, and the Restart Programme ${ }^{8}$ which provides incentives to employers to hire and retain older workers. Policy measures to support participation need to be viewed in conjunction with support for movement of participants into employment rather than unemployment.

\subsection{Robustness}

The point estimates of the Okun coefficients made here for Australia and shown in Table 2 are somewhat higher (absolute) than other estimates in the literature (for example 0.67 for all persons vs. 0.54 by Ball et al. (2013), 0.40 by Borland (2011) and 0.35 by Lancaster and Tulip (2015)), noting that estimates for Australia are already at the high end of international estimates (for example, most countries in a group of 20 advanced countries had an estimate in the range 0.23-0.54 (Ball et al. 2013) and Dixon et al. (2017) made an estimate of 0.48 for a panel of 20 OECD countries). This could reflect the particular sample period, the decomposition methodology or conceptual differences between what the coefficient measures in different forms of analysis. In this paper, the coefficient has a specific meaning which can be interpreted as the ratio of the amplitude of a common business cycle component which is shared by unemployment and output.

To perform a reasonableness test for the particular sample period, we derived another, simpler estimate of the Okun coefficient for all persons by calculating the long-run multiplier as defined by Eq. 3. Using quarterly data from the same sample period of September 1980 to June 2017 and a regression of $\Delta u_{t}$ on $\Delta y_{t}$ with one lag of $\Delta u$ and three lags of $\Delta y_{t}$ as explanatory variables generated an estimated long run multiplier of -0.48 (see Table 3 ), which is comparable with typical estimates of the average Okun coefficient for an OECD country.

Many authors have used a HP filter to extract the cyclical components of one or more elements used in the estimation of the Okun coefficient (for example, Dixon et al. (2017) and Ball et al. (2013)) so we also consider the impact of the chosen model against the HP filter. The empirical model framework in this research can be used to generate an alternative set of estimates of the Okun and participation coefficients consistent with the use of the HP filter for the trend and cycle decomposition. It is well known that the HP filter can be represented

Table 3 Estimation of the long-run multiplier

\begin{tabular}{llll}
\hline Dep. variable $\Delta u$ & Coeff. & Std. Error & $p$ value \\
\hline Constant & 0.2725 & 0.0477 & 0 \\
$\Delta u(-1)$ & 0.2560 & 0.0810 & 0.0019 \\
$\Delta g$ & -0.1144 & 0.0269 & 0 \\
$\Delta g(-1)$ & -0.1409 & 0.0279 & 0 \\
$\Delta g(-2)$ & -0.0455 & 0.0298 & 0.1291 \\
$\Delta g(-3)$ & -0.0577 & 0.0272 & 0.0356 \\
Long-run multiplier & -0.4820 & & \\
LM(4) & 5.0408 & & 0.2831 \\
LM(12) & 13.8881 & & 0.3079 \\
\hline
\end{tabular}

Breusch-Godfrey serial LM(n) test. No serial correl. up to $n$ lags 
in state space form with an underlying process which is the sum of an integrated walk and an irregular component (which is interpreted as the cycle) with a restriction applied to the ratio of the slope and irregular variances which imposes a level of smoothness on the trend (Harvey and Trimbur 2008). Table 4 illustrates the estimated Okun and participation coefficients with a version of our model modified to match the HP specification of the trend and cycle components using a typical value for the smoothness parameter ${ }^{9}$. The Okun and participation coefficients are calculated as the ratio of the standard deviation of the relevant cycle to that of the output cycle. Full results for the model estimation are not shown ${ }^{10}$.

This procedure has generated estimates of the Okun coefficients which are comfortably within the range of the estimates of the other cited authors (notwithstanding other significant differences in methodology to those studies cited). This suggests that the particular UC decomposition methodology used in this research, with freely estimated variances for trend and cycle components rather than those imposed by the restrictions embedded in a HP specification, is responsible for the higher absolute estimates of the Okun coefficients.

\section{Conclusions}

We have used a multivariate unobserved components model to decompose output and three labour markets time series in Australia into trend and cycle components. A key assumption used for identification was that the series share a common business cycle component. The model framework provided a direct estimate of the sensitivity of the labour market series to cyclical output shocks. The results were used to generate estimates of the Okun coefficient and a participation coefficient by age and gender. The estimates of the Okun coefficient are higher (absolute) than those generally reported in the literature which was attributed to the decomposition methodology. The unobserved components model finds maximum likelihood estimates of the components in contrast to more typical cycle extraction using the HP filter. The variation in the absolute values of our Okun coefficients by age and gender tends to follow the pattern found in the literature, with higher values for males than for females, notably higher values for the youngest age group and which tend to decline with age thereafter. Participation is less cyclical than unemployment but the coefficients are positive (it is procyclical) and mostly significant apart from males in the middle age groups. Participation is more cyclical for females than males, particularly in the middle age groups. Taken together these results show that, in aggregate, males in the middle age groups tend to stay in the labour force throughout the business cycle, perhaps moving between employment

Table 4 Okun and participation coefficients derived using HP filter specification

\begin{tabular}{|c|c|c|c|c|c|}
\hline \multirow[b]{2}{*}{ Group } & \multicolumn{3}{|c|}{$\begin{array}{l}\text { Cycle innovation } \\
\text { std. dev. }\end{array}$} & \multirow{2}{*}{$\begin{array}{l}\text { Okun } \\
\text { Coeff. }\end{array}$} & \multirow{2}{*}{$\begin{array}{l}\text { Partic. } \\
\text { Coeff. }\end{array}$} \\
\hline & $u_{t}$ & $p_{t}$ & $g_{t}$ & & \\
\hline Persons (all age) & 0.568 & 0.277 & 1.162 & 0.49 & 0.24 \\
\hline Male (all age) & 0.669 & 0.251 & 1.162 & 0.58 & 0.22 \\
\hline Female (all age) & 0.466 & 0.357 & 1.162 & 0.40 & 0.31 \\
\hline
\end{tabular}


and unemployment, whereas females of the same age have a higher tendency to move in and out of the labour force procyclically. This has policy implications for attempts to increase the rate of participation of particular groups by gender and age following a cyclical downturn.

\section{Endnotes}

${ }^{1}$ The participation rate is the percentage of the civilian population who are in the labour force, which comprises employed and unemployed persons. People who are not working and not actively looking for work are not in the labour force.

${ }^{2}$ If the empirical relationship between output and unemployment is negative as anticipated then the estimate of $\beta$ in Eq. 1 would be a positive number. In the literature the Okun coefficient may be reported as a positive number, and at other times as the negative value $-\beta$.

${ }^{3}$ The Australian Bureau of Statistics report monthly gross flow data for the labour market in Catalogue 6202, data cube GM1. The data measures the gross flow of workers in both directions between each of the labour market states of employment, unemployment and non-participation, by comparing the status of matched respondents in a monthly survey which make it possible to determine whether a transition of a worker between states has occurred within the period.

${ }^{4}$ Variance parameters were estimated as the argument of an exponential function to ensure that estimated variance was greater than or equal to zero.

${ }^{5}$ Some parameters such as correlation coefficients were estimated as the argument of a logistic function so that the parameter would be constrained to lie between a specified lower and upper bound.

${ }^{6}$ The higher standard errors of coefficient estimates for the oldest female group is thought to reflect noisier data from the generally small number of participants in this group. The point estimate of the participation coefficient is positive $(0.20)$ but it is not significant.

${ }^{7}$ Analysis of the cost effectiveness of subsidised child care is complex, since there is likely to be interaction between tax and welfare policies which may encourage shorter working hours for second income earners within a family unit. Further, subsidised childcare without an activity test may in fact discourage participation (Productivity Commission 2014, 2).

${ }^{8}$ Details of the Restart Programme of employment assistance can be found on the website of the Australian Government Department of Jobs and Small Business website at https://www.jobs.gov.au/restart-help-employ-mature-workers-0.

${ }^{9}$ For monthly data a smoothing parameter of 14400 is sometimes suggested for the HP filter, although there is no general agreement as to the best value for this parameter. The parameter setting will generate a relatively smooth trend and allocate deviations from this trend to the cyclical component.

${ }^{10}$ The log likelihood at the solution was materially lower than that obtained for the original model, indicating that the smooth trend plus cycle model was a poor fit to the data. A substantial improvement in the log likelihood was seen when the ratio of the variances was freely estimated, but the fit was still materially worse than that for the original model. 


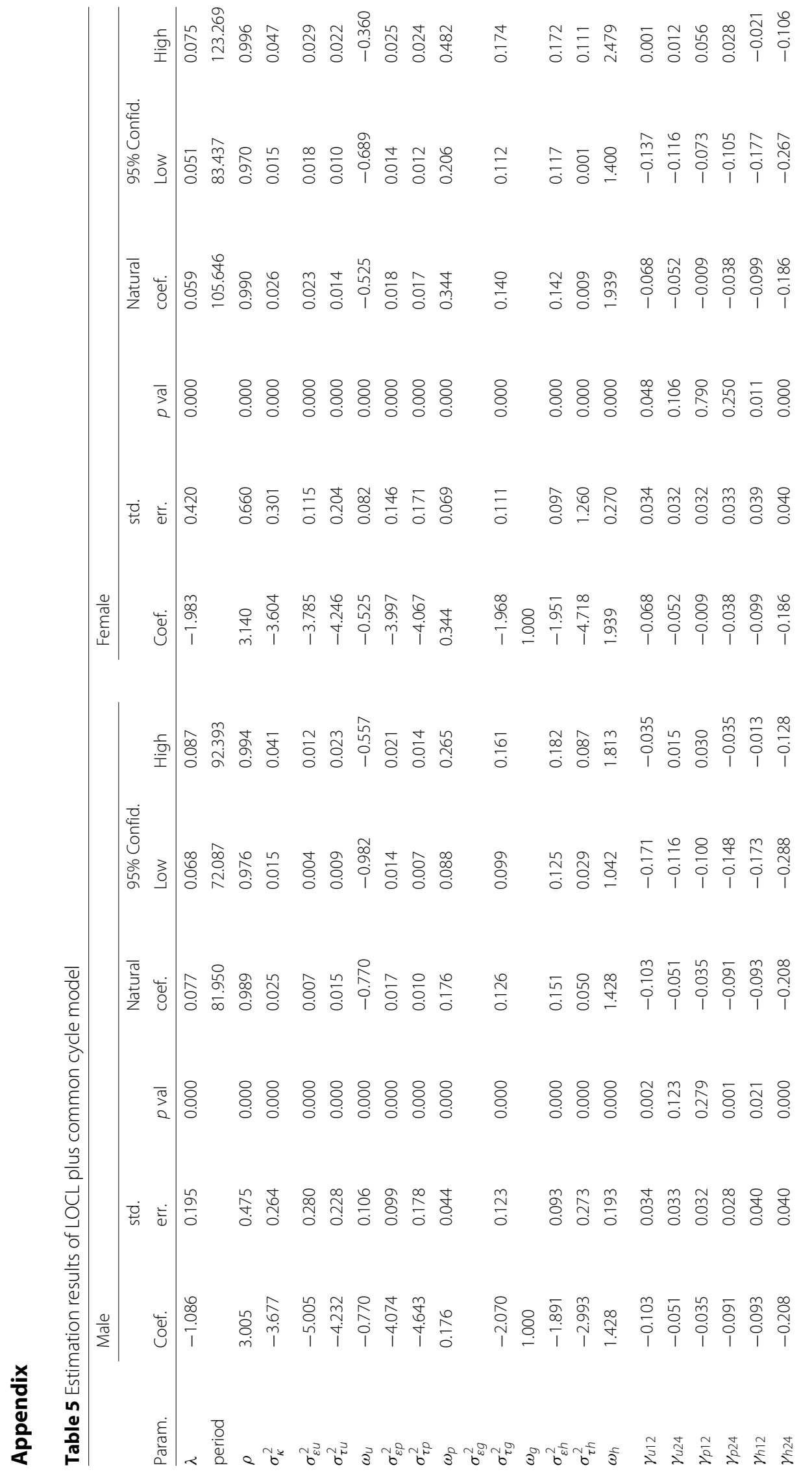




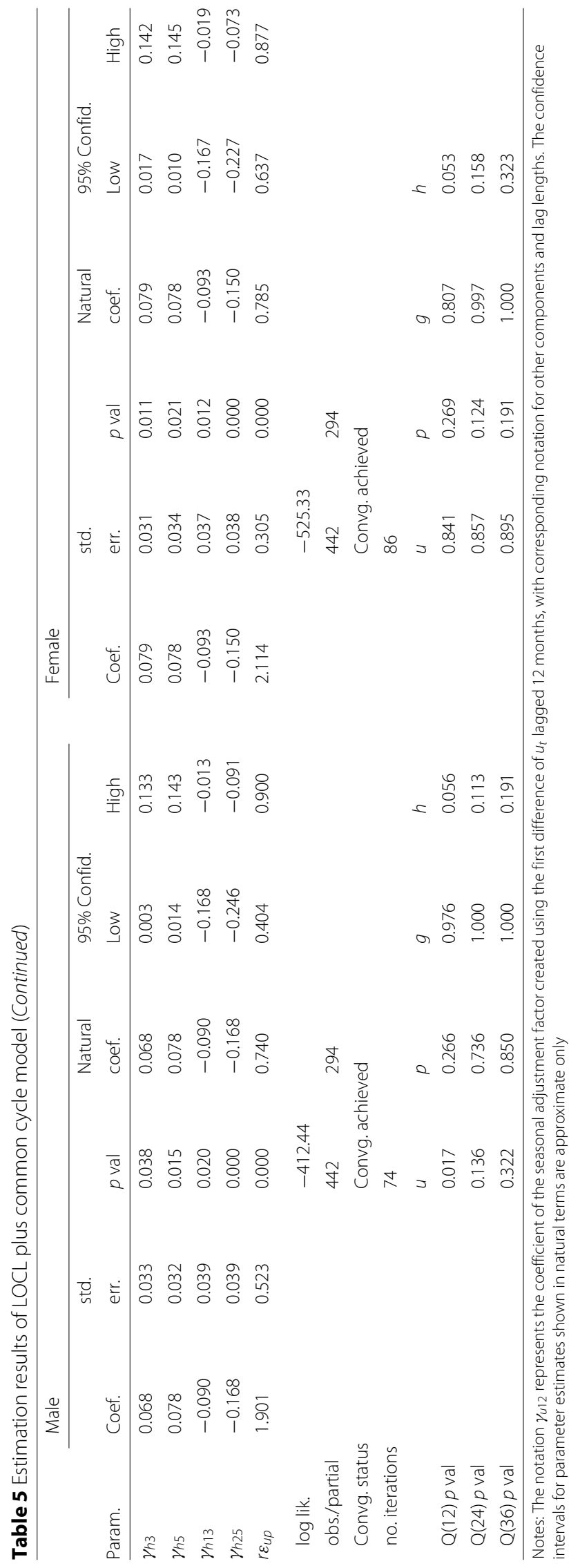


Table 6 Data sources

\begin{tabular}{|c|c|c|c|}
\hline Series & Group & Source & Notes \\
\hline $\begin{array}{l}\text { Unemp. rate, Particip. } \\
\text { rate. }\end{array}$ & $\begin{array}{l}\text { Persons, males, } \\
\text { females. }\end{array}$ & $\begin{array}{l}\text { ABS Catalogue } 6202 \\
\text { Table } 1\end{array}$ & $\begin{array}{l}\text { Seas. adj. monthly series. When } \\
\text { required, quarterly series created } \\
\text { using average of } 3 \text { months. }\end{array}$ \\
\hline $\begin{array}{l}\text { Unemp. rate, Particip. } \\
\text { rate. }\end{array}$ & $\begin{array}{l}\text { Males and females in } \\
10 \text {-year age groups. }\end{array}$ & $\begin{array}{l}\text { ABS Cat.6291.0.55.001 } \\
\text { Data cube LM1. }\end{array}$ & $\begin{array}{l}\text { Original terms. Seas. adj. } \\
\text { series were generated using } \\
\text { X12-ARIMA. }\end{array}$ \\
\hline Gross Domestic Product & - & $\begin{array}{l}\text { ABS Catalogue } 5206 \\
\text { Table } 2\end{array}$ & $\begin{array}{l}\text { Real, seasonally adjusted. } \\
g_{t}=100 \ln (G D P)\end{array}$ \\
\hline $\begin{array}{l}\text { Mthly. hours worked } \\
\text { in all jobs. }\end{array}$ & Persons & $\begin{array}{l}\text { ABS Catalogue } 6202 \\
\text { Table } 19\end{array}$ & $\begin{array}{l}\text { Seas. adj. A dummy variable } \\
\text { was used to remove outliers } \\
\text { in June } 1979 \text { and June } 1980 . \\
h_{t}=100 \ln (\mathrm{MHW})\end{array}$ \\
\hline
\end{tabular}

\section{Acknowledgements}

The author would like to thank Lance Fisher, Ben Wang, Jonas Mansson and seminar participants at the Western Economic Association International 14th International Conference at the University of Newcastle, Australia, for helpful discussions on the earlier drafts. The author would also like to thank two anonymous referees and the editor for helpful suggestions to improve the paper.

Responsible editor: Pierre Cahuc

\section{Availability of data and materials}

All of the data used in this report is available from the website of the Australian Bureau of Statistics at www.abs.gov.au. For more details refer to Table 6 in the Appendix.

\section{Competing interests}

The IZA Journal of Labor Economics is committed to the IZA Guiding Principles of Research Integrity. The author declares that he observed these principles.

\section{Publisher's Note}

Springer Nature remains neutral with regard to jurisdictional claims in published maps and institutional affiliations.

Received: 1 February 2018 Accepted: 30 May 2018

Published online: 28 June 2018

\section{References}

Ball LM, Leigh D, Loungani P (2013) Okun's Law: Fit at 50? Working papers, The Johns Hopkins University, Department of Economics. w18668

Benati L (2001) Some empirical evidence on the 'discouraged worker' effect. Econ Lett 70(3):387-395

Blanchard OJ, Diamond P (1990) The cyclical behavior of the gross flows of U.S. workers. Brook Pap Econ Act 1990(2):85-155

Bodman PM (1998) Asymmetry and duration dependence in Australian GDP and unemployment. Econ Rec 74(227):399-411

Borland J (2011) The Australian labour market in the 2000s: The quiet decade. In: The Australian Economy in the 2000s, Proceedings of a Conference, Reserve Bank of Australia, Sydney. pp 165-218

Commandeur JJ, Koopman SJ (2007) An introduction to state space time series analysis. Oxford University Press, Oxford

Commonwealth of Australia (2015) 2015 Intergenerational Report: Australia in 2055. Commonwealth of Australia, Canberra

Cuaresma JC (2003) Okun's Law revisited. Oxf Bull Econ Stat 65(4):439-451

Darby J, Hart RA, Vecchi M (2001) Labour force participation and the business cycle: A comparative analysis of France, Japan, Sweden and the United States. Jpn World Econ 13(2):113-133

Dellas H, Sakellaris P (2003) On the cyclicality of schooling: theory and evidence. Oxf Econ Pap 55(1):148-172

Dixon R, Freebairn J, Lim GC (2004) A framework for understanding changes in the unemployment rate in a flows context: An examination net flows in the Australian labour market. Research paper no. 910. Department of Economics, University of Melbourne, Melbourne

Dixon R, Lim GC, Van Ours JC (2015) The effect of shocks to labour market flows on unemployment and participation rates. Appl Econ 47(24):2523-2539

Dixon, R, Lim GC, Van Ours JC (2017) Revisiting the Okun relationship. Appl Econ 49(28):2749-2765

Duval R, Eris M, Furceri D (2010) Labour force participation hysteresis in industrial countries: Evidence and causes. Report, OECD Economics Department, Paris

Elsby MWL, Hobijn B, Sahin A (2015) On the importance of the participation margin for labor market fluctuations. J Monet Econ 72:64-82

Erceg CJ, Levin AT (2014) Labor force participation and monetary policy in the wake of the great recession. J Money Credit Bank 46(S2):3-49 
Hamilton JD (2017) Why you should never use the Hodrick-Prescott filter. Report. National Bureau of Economic Research. Cambridge

Harvey AC (1985) Trends and cycles in macroeconomic time series. J Bus Econ Stat 3(3):216-227

Harvey, AC (1993) Time series models, 2nd edn. Harvester Wheatsheaf, Hertfordshire

Harvey AC, Jaeger A (1993) Detrending, stylized facts and the business cycle. J Appl Econ 8(3):231-247

Harvey AC, Trimbur T (2008) Trend estimation and the Hodrick-Prescott filter. J Jpn Stat Soc 38(1):41-49

Holmes MJ, Silverstone B (2006) Okun's law, asymmetries and jobless recoveries in the United States: A Markov-switching approach. Econ Lett 92(2):293-299

International Monetary Fund (2010) World economic outlook, April 2010, Rebalancing growth. Report. International Monetary Fund, Washington, DC

Jaeger A, Parkinson M (1994) Some evidence on hysteresis in unemployment rates. Eur Econ Rev 38(2):329-342

Lancaster DP, Tulip P (2015) Okun's law and potential output. Research discussion paper. Reserve Bank of Australia. RDP 2015-14. Sydney

Lee J (2000) The robustness of Okun's law: Evidence from OECD countries. J Macroecon 22(2):331-356

Mincer J (1966) Labor-force participation and unemployment: A review of recent evidence. In: Gordon RA, Gordon MS (eds). Prosperity and unemployment. Wiley, New York. pp 73-112

Moosa IA (1997) A cross-country comparison of Okun's coefficient. J Comp Econ 24(3):335-356

Morley JC, Nelson CR, Zivot E (2003) Why are the Beveridge-Nelson and unobserved-components decompositions of GDP so different?. Rev Econ Stat 85(2):235-243

Nickell S (1997) Unemployment and labor market rigidities: Europe versus North America. J Econ Perspect 11(3):55-74

Okun AM (1962) Potential GNP: Its measurement and significance. In: Proceedings of the Business and Economic Statistics Section. American Statistical Association, Washington, D.C. pp 98-104

Pelagatti MM (2016) Time series modelling with unobserved components. CRC Press, Taylor and Francis Group, Boca Raton

Ponomareva N, Sheen J (2013) Australian labor market dynamics across the ages. Econ Model 35:453-463

Productivity Commission (2014) Childcare and early childhood learning. Report. Productivity Commission, Report No. 73, Canberra

Proietti T (2004) State Space Decomposition Under the Hypothesis of Non Zero Correlation Between Trend and Cycle With an Application to the Euro-zone. In: GL Mazzi, et G. Savio (eds). Monographs of Official Statistics, Papers and Proceedings of the Third Colloquium on Modern Tools for Business Cycle Analysis. European University Institute, Florence. pp 292-325

Sinclair TM (2009) The relationships between permanent and transitory movements in US output and the unemployment rate. J Money Credit Bank 41(2-3):529-542

Van Zandweghe W (2012) Interpreting the recent decline in labor force participation. Economic review. Federal Reserve Bank of Kansas City, Kansas City

Zanin L (2014) On Okun's Law in OECD countries: an analysis by age cohorts. Econ Lett 125(2):243-248

\section{Submit your manuscript to a SpringerOpen ${ }^{\odot}$ journal and benefit from:}

- Convenient online submission

- Rigorous peer review

- Open access: articles freely available online

- High visibility within the field

- Retaining the copyright to your article

Submit your next manuscript at $\gg$ springeropen.com 